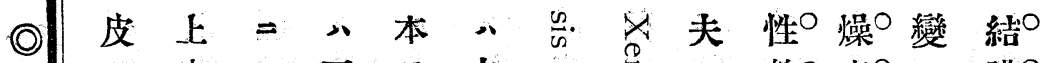
結 $=$ 皮 $=$ 五 日

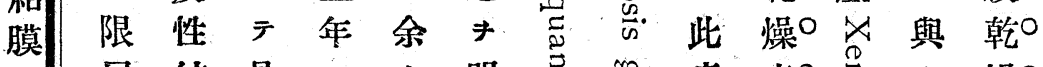
乾 局結是, 力 眼 燥 $>$ 膜 $\Rightarrow$ 男 諸 乾。

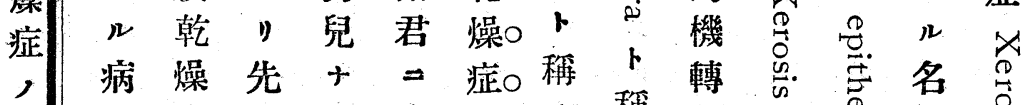
节變症 $\neq$, 示

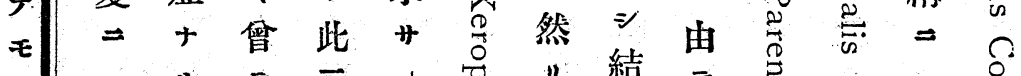

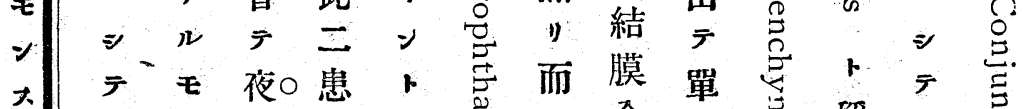

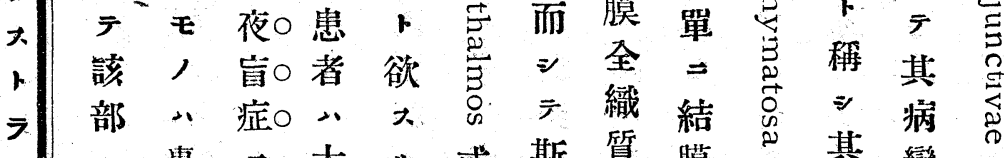
4 - 專 $=$ 大 $⿻$ 或斯質膜 2 其變

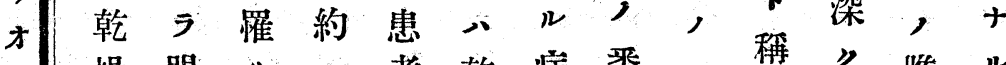

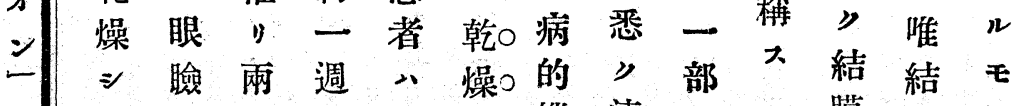
テ 孔 症 間 福 眼。機連, 䤞二共前田炎。轉累; 暗 相 $=\exists$ 會 $\rtimes=t$ 侵 、對今日有号由 十 万倘上兒总り品 》几林皮院志本、三

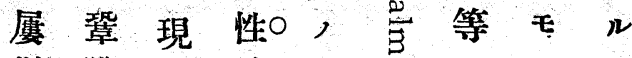

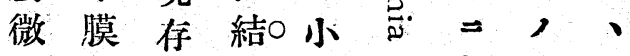
細 部 た 膜○兒ト角 $+\neq \sim$ 乾。 $=$ 稱膜之,

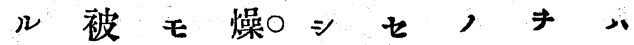
泡 覆, 症。 声浗

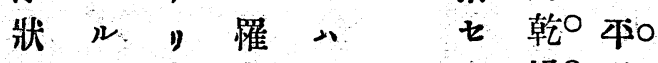

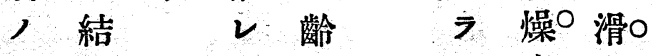
白膜 $\sim$ 四、症 ${ }^{\circ}$ 乾。 色, モ年东燥。 點 上, 一, 0 症。 結 膜 乾 燥 症 $\frac{3}{\vec{T}}$ モ

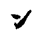
大 1 7 4 オ 組 織 面 $\neq \quad$ 結

侵 : 畭 壟限蹦 談 大局 話 ル局 モ 光 本= ，於 ○, 斗野 之一失

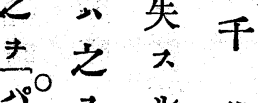
20 上0- 代 。皮 七性。，

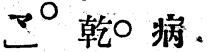


本結組 : 余於荅兒該 $\neq ル \neq$ 運其

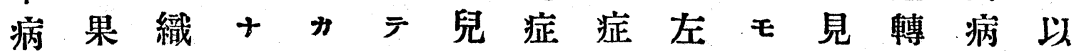

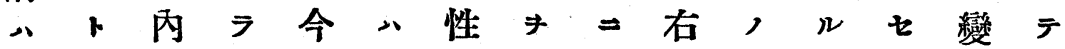

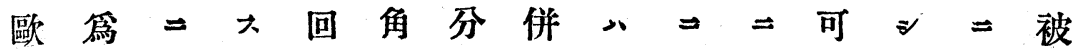
米 万分其本膜泌發著運在 人可布色口患, 物 ， キ、澤者內 實 $+\cdots$ 變○ $\Rightarrow$ 側認，分 $\approx$ 結是結 $ઋ$ 驗》血 $=0$ 就三山劇泌山膜本膜見,

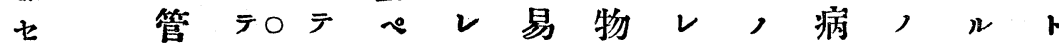
ル, 污○殊 У 氏 $氏$, 八内, 内可大 所循穢○七他關夥多㫮診㫮》 今 二 環 鉛○泩グ, 係多少或斷及眼此 據機色口目 즈、 レ障 $\neq 0 \approx \approx$ 名 $ッ$ 大外最外結者

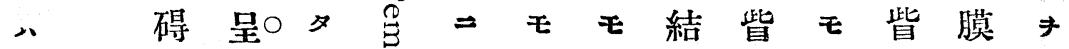
屡 = $\dot{2}^{\circ} n$ 它於, 膜部注部心一

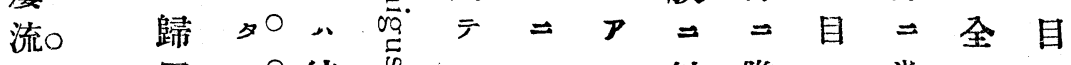
行O 因 20 結 病家大, $大$ 膜

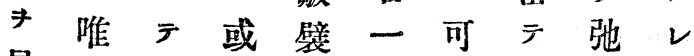
見僅本

發 則 是 $=$

三千結 鈍

或營 膜 暗

八. 養及

亦不 $七$ 第

散○ 給 結 $レ$

在○，膜

病。一下,

二患 然 放 平 要 膜 $三$ 殊

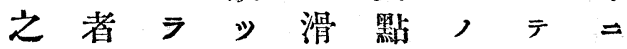
中， 百面二左寬結 見其 $ル, \neq=$ 右鬆膜 ル 一 モ 認 $テ$ 側卜， , 名, ”中乾 $\Rightarrow$ 篇外 ～$=\boldsymbol{>} ル$ 燥著 其於》，症 $三 n$ 部 他 $\overline{\text { 盖 } \mathbf{z}, ~}, \neq=$

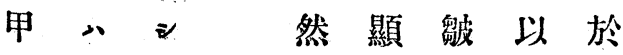
人著是 レ著譬 患 $=$ 氏 $上+$ 眼著 者》加 眼亏放球 $=$ 加荅 球 $\# \% *$ 


\section{三六一一 記筆說演告報會究研事醫堂天順}

(0) 夜本 2 從甚營七多 $\neq=$ 否 2 都患

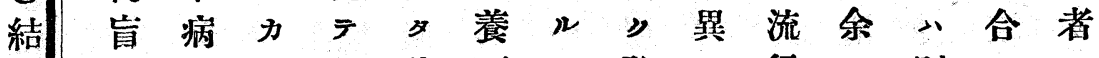

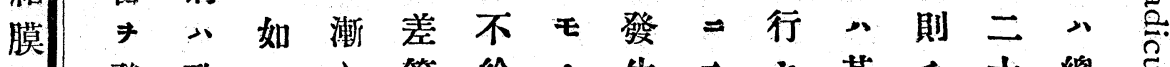

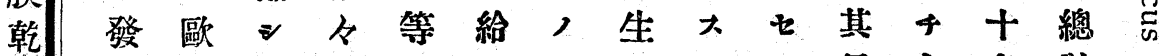
燥 $=$ 米 $卜$ 消 $>，=N n$ 侵七名計卜

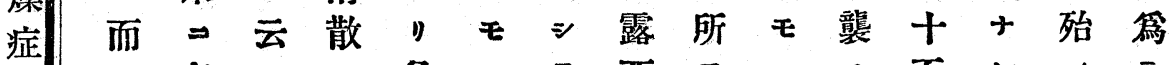

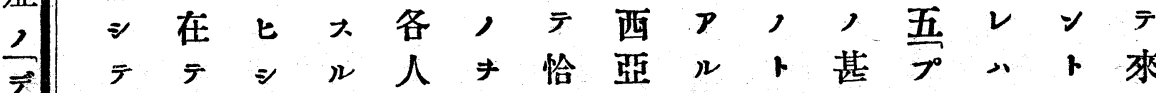
後所 $\Rightarrow$ 侵 $匚=$ 第 $\Rightarrow$ 其十 - 一 夜謂常於三他於如大多七殆五７

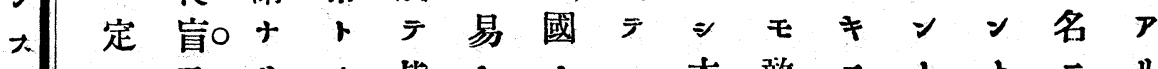

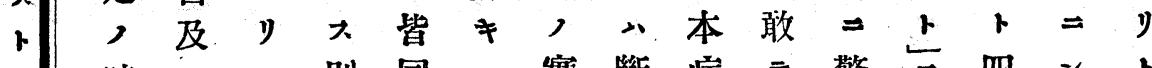

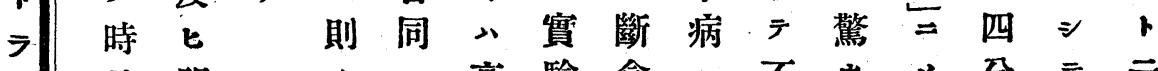

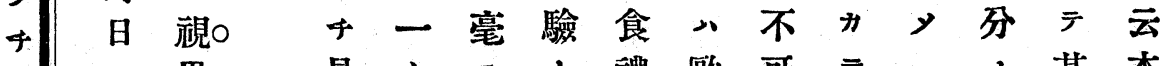

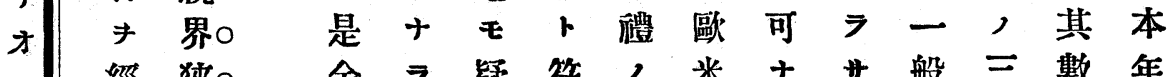
二 經 陝。余 7 疑 符, 米ナ甘般三數 年 テ 縮○ カ

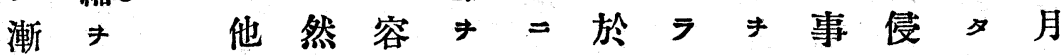
々併, レル合多 $テ ン$ 得卜襲僅以 上發流氏 可 た $\approx$ 川 \# オ

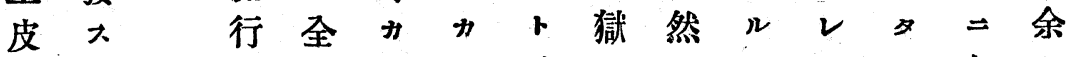
性 $n$ 病身 $\Rightarrow$ 如云舍 $v+\cdots n$ 失” 乾飞、, \#止兵氏》决 燥, 少營几是余營普是 $\approx$ 以田 症多 $三$ 養ナ * $三 \quad \geqslant y$ 由患, , 以小之如育 發卜 其改而 $テ$ 者劉流 云趣艮 桃余 $\neq>F \neq$ 亦及病 $\neq$ y分踓 $=$

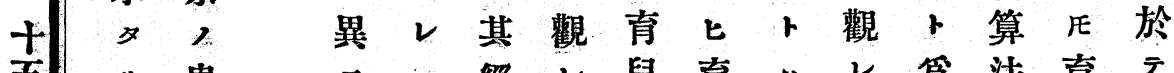

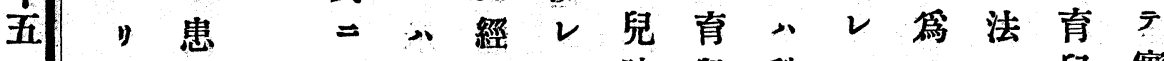
シ者 大病過入院兒稍川

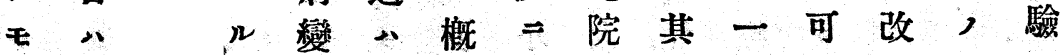
, 最所も長 $\triangleq$ 發等趣部カ算全 二初》亦短文生 $=\neq$ 落 


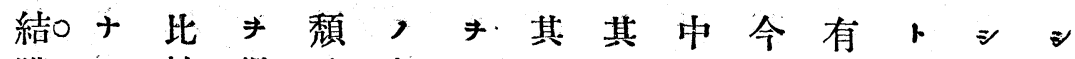
膜口り較得潰角留周中其回無 大該 乾○的 $₹$ 顯膜山線心,$-=2$ 症夜 燥○佳 全 著 潰 $モ き$ 名患就 $ヤ=$ 旨

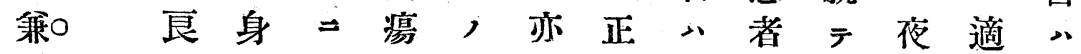

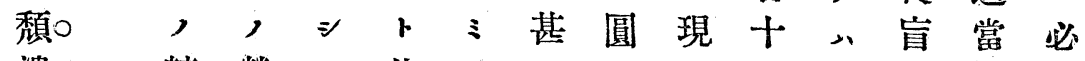
潰 轉營 $\bar{\gamma}$ 其 $=3+=$ 五未先, 性○歸養已趣過大心角名》ッ治乾 角口 $\neq$ 善 $=\neq \neq+$ 一膜中之消法燥

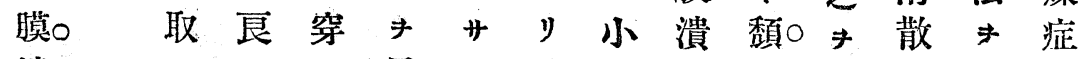

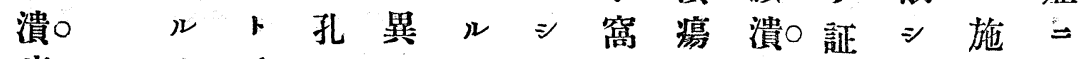
瘍 モ 篇 七

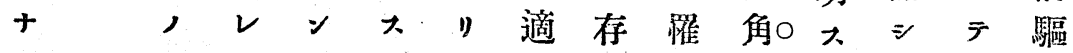

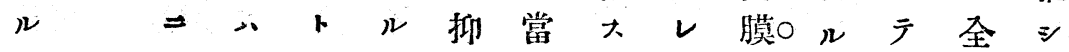

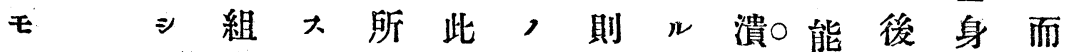
， $＼mathrm{~ 織 ~}$ 兮治, 办, 療是, $\Rightarrow$, 燥營 $>$ 後 頽 如 其 潰 $\Rightarrow$ 其 $=$ 罹 $y$ 症 養 後

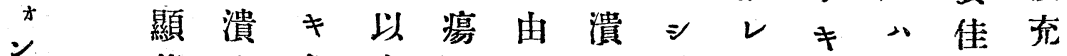
分著止危他 》リ瘍 レノミ險 $+ル$ 漸 $=$ 角 $モ$ 澥從 $>=$ 余令

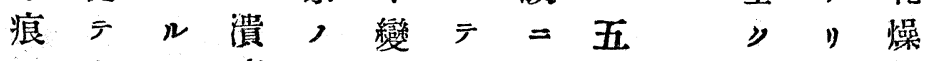

至 $\quad$ 漸 $カ$ 瘍實小最八名治結症

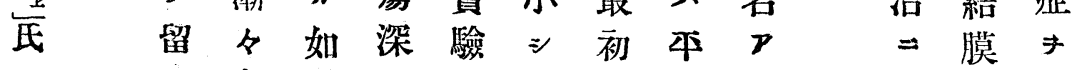
４角 $\neq$ 》 、 $テ$ 、等口就, 發

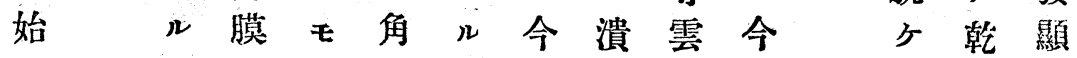
メ 八組, 膜所入湯霧諸》懆 $\bar{*}$ 甚 織 $卜$ 組 $\Rightarrow$ 則底狀君

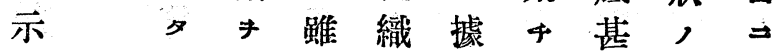
定稀再氏 $た$ 此园示 七有成治荒入一深濁七 $n+\approx$ 療摔大小, 所 $⿻$ 以其 $=\Rightarrow$ 凹且有患 人 是广當其他简 但 將 $\geqslant=r$ 視 治 $\overline{7}$ 界 $\Rightarrow$ 之 狹 就 縮 力持 
五六一一 記筆說演告報會究研事醫堂天順

(2) 食余レ本、然或差 差殆角變間症

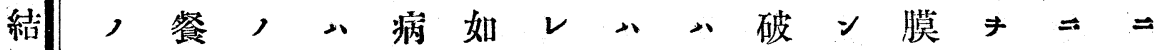

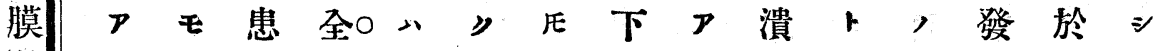

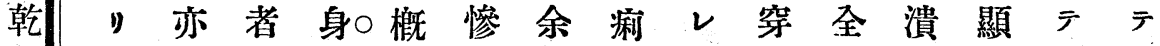
燥 $=$ 常, $10 \geqslant$ 狀, 等 $v 孔 \geqslant$ 瘍 $三$ 甚歐

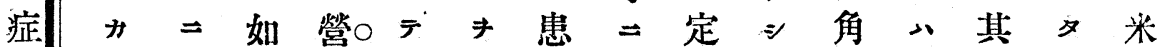

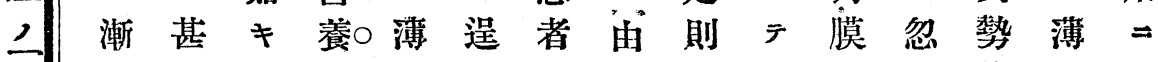

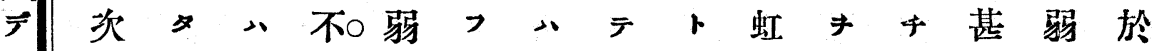

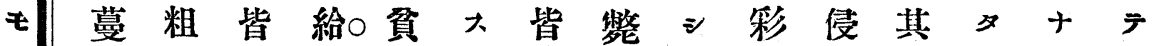

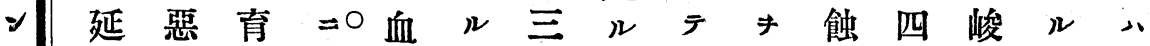
大. $=+$ 兒 其 $0=$ 年、必脫 $=$ 隣劇營甚

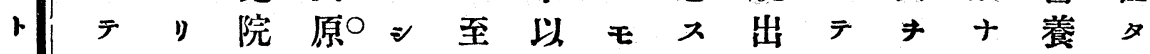

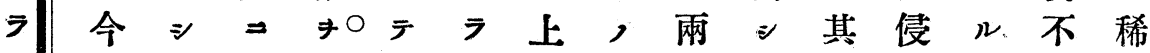
4 小十生取全 $、$ 七 オ殆り活か○身適年 大 こン加を モ○, 當以侵全部热

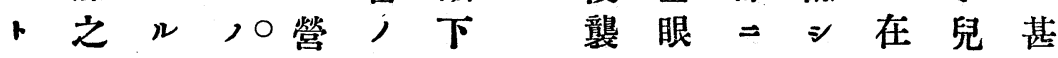
全昨モ》0養治, 入球唯テデ 員年, 20 缺療小可苝細浸

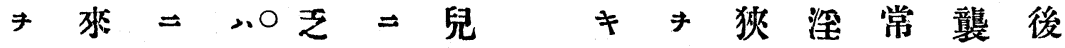
侵三 $三$ 毫七问 $=$ 併, $\Rightarrow= \pm$, シ三テモ○ルテシ，發一罹虹最不

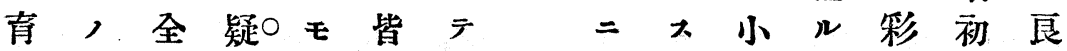
兒有身 $\neq 0$, 悉幸 $\approx$ 加輪角 $\neq$ 角十

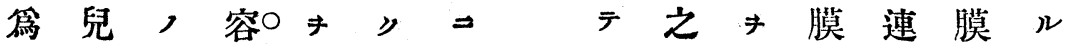
メ = 營 $n \circ$ 侵治歐患本殘板累, 疾 ，寄䬭可○襲 $=$ 米者病留層 或 生 概 カ○大就人 “性 $三$ ラ०几,

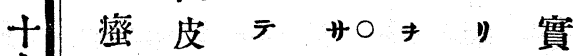
七䬸 疹善 或 八發十》○之 疼七 7 殊 $\neq$ モ 痛少二見， 八川大ま忩 殆常儿壤虹或屬 У $\Rightarrow$, 死彩山 卜 多 : $\Rightarrow$ 悠 其 常少角陷 $\neq$ 近後

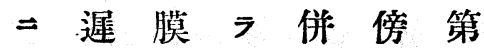
肺速 . $\approx$ 發 $=$ 炎, 終 邓三病年 
八實アナル故二因 斯 驗り ル 能

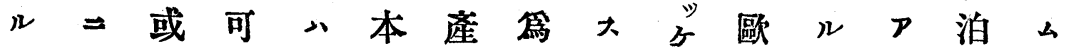
異 常 $心$ 日其其 ,末》他將全第キ心發於

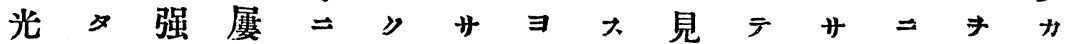
線此光本怙全、》余 刺等, 病死身上モ, そ本十回へ シ

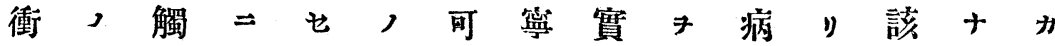
二事接併 ン營カカ口驗以患 關實之發・養 係 大証力或ル給ル結

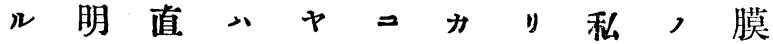
士 $、$ 接之生原如

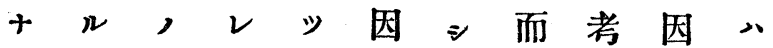
》能原 $=$ 皮

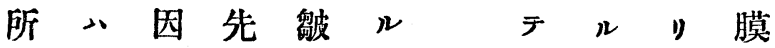
謂フ十羂 ミ モ 血余 $ラ$ 葉, 液 $夫>ル$ 稠 循以上莅山 環 夫皆トテ 機之レ症一恰 衰 ま或二般モ 弱 觀 $心$ 就其草 ノ 然 $テ$ 理木 結 果此 ン 説同養 卜種 然 $\neq>$ 液 篇, レ雼 テ夜代 フ、攝 承旨余 モ モ 取 夕症, ,
後 二 ト 潰 此此主瘍 二 等 張 $\exists$ 寄, 大 》 生 $心$ 以 シ モ 種 タテ, 2 17 य० モ $\boldsymbol{P}$ 》 , 然 盖レレ シシ モン テ本末交 即病 比 千, 容疍 第原易》
院 小 小

ヨ疲看 》疹 護 多 乇䀦 數 從 私 , $=$ 患溜 思 者散 〜 F $\overline{7}$ 出叫 三十魚 タ ラ 類 ル $ン$ 或 八 1 盖依 油 シ テ 質 是籓 類 杯 $=$,

厭 禁 食 法厭物 , 法 $\%$ 結 $ま$ 禁 果 斷 $=$ 卜行 勉 云 $三 x$ 


\section{七六一一記筆說演告報會究䂰事醫裳天順}

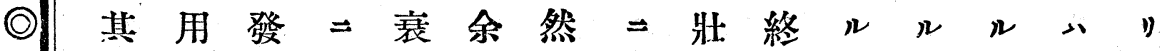

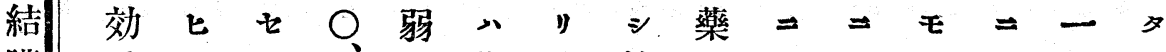
膜 驗 或 $\bigcirc$, 糹上適

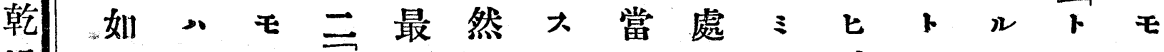

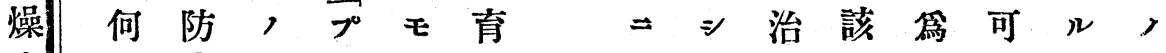
症 $\neq$ 腐之甚兒之以法症サキポ 1 知繃 踓七夕院 デ モ $、$ 亦卜キ食

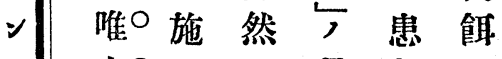
ㅊ 本七り昇兒

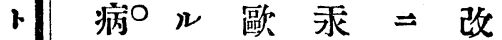
ラ, 0 千 米溶 千 治 ${ }^{\circ} \Rightarrow$ 液 4 米 オ療○ア $\boldsymbol{7}$ 学 テ ン $\mathbf{1}^{\circ}$ 》 $-\neq$ 食 其○然此 日. 攝 餐 効○ $レ$ 種 數 取 驗蚱, 回七牛 , ○余角點 最 小膜 眼 メ 瀂 モ○未潰七タ肉 顯○»瘍 シ 》肉 著○之 $之$ 其美 ナ○ま温 又他汁

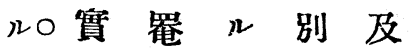
モ๐驗 法, $\Rightarrow$ 七 , 0 或 : 藥 油 ト○徽 小危劑質 十 =0セ防膜 $;$ 等 九 テ○サ腐 = 與 ま 固○ル眔潰 〜供 クナキ法演 だ セ 信○以等 ま 只 シ シ0テ ま併眼 メ

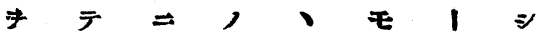
保可就渻止 護及 $及$ 散可 $ヨ$ 乾 フ、的一七カy号燥

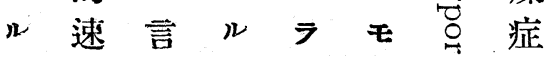

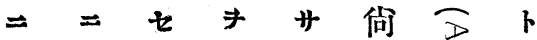
$\boldsymbol{\gamma}$ 全ン以ル站同 y 身 $=$ 十 異 合 $=$ 角, 泰飞り常官》 膜 營 西亦盖 $\Rightarrow$ 全 $\Rightarrow$ 養諸其 $シ$ 强, 身 頽 $\neq$ 家然是 ₹ 狀, 潰回, ル適光態營 性復筫可當線、養 潰七驗 ₹ 演ンス所治衝り給 * 7 以 療 $\neq$ 以 $\Rightarrow$ 併 $夫$ 所, $=$ 要 $\bar{之}$ 發是 $\Rightarrow$ 理由 セ器 七務 テ $n \times>$ 証全 $几$ 生原 モ而滋明身，可理， フ $三$ 養入, 分的取

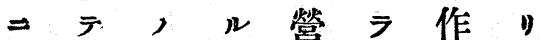
於眼食 $\Rightarrow$ 養 \#用篇 テ自慨足佳ル $ル$ 八未及心底 $=$ 急 $\Rightarrow$ 殊安七可上至起網

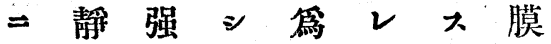


出》問抑 $大$ 大人》膜 $\approx$ 余, シリ ‘モ可當, 醫潰カ山ナ見併疑

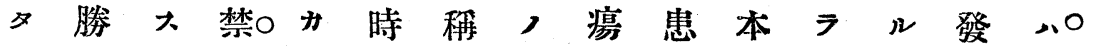

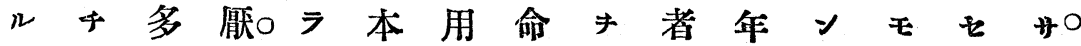

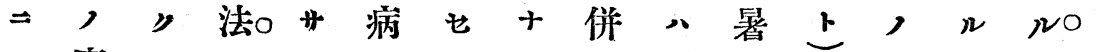
ア事 ル十ル ル ルリ發三休 ラ十之ル十斯无卢四 $=$ スり $\mapsto$ 現由, 療上魚次, 東 $\Rightarrow$ 小 法 小類 $モ$ 或 京福治本 夫九及, 兒上

二田大邦 於會 $n=$

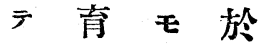
佾兒, 厂 米院卜 、 且 $=$ 篇 太 》於 $三$ 古 此 广習 神 讐学用代 $>$ 此, 醫

》禁 久道 况嬮 $三$, ン法 キ 遺 $\vec{\nabla}=$ 信 法 寒由用 $=$

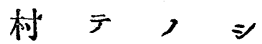
䑀多厚 鄓 數 $\neq$ 疾 , , 俗病 地本間， 方病二何 二患入 於者隨几 $\bar{F} \neq$ 分
施 $\vec{\nabla} ヒ+=$ 地 大反油り モ街 質 $\neq \bar{\sigma}$ , 十類之當旅 P $)$ 二時行 于若食食峻中 ンシ慨慨劇人 卜果 $\neq$ 及, 八三嚴七上依 實 テ禁一皮賴 二是三般性 怪醫眼，結應 訝, 二攝膜 二命冷生幹 $\overline{-}$ 堪十罨法燥二 几 》法 ま症三 \# $1 \Rightarrow$ 問 $=$, 几七施 7 羅本 $+\cdots t=$ "病 》徃”患居患 否時卜兒》著 毫》方, 已 モ知令母 $=$ 診 信 三吾日角
○ 如, 聯○

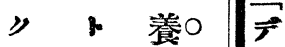
豫 踓 强○モ 後芷 壯O , 速，， 不 $=$ 食○叔 艮 食 飭门 十飭 10 千 $\pi \neq \leqslant 0$ オ モ 改 $=0$ , 良 $>0$ $=\quad \geqslant 0$ 非 余 ラ 攝 い 大. 生 斷 シ 法 言 F $\neq$ 意 遵 本 外守病 二 七 八 佳 き 設 层メ ノ八頽 轉 盖 潰 歸 $=$ 性 夫歐 角 取 米 膜 $n=$ 潰 千於瘍 
九六一一記筆說演告報會究研事醫堂天順

(a) 2 今 年モ十昨

向, 年, , 几冬

三 流後殆

$>+$ 行 $>2$ 知秝

フ三人再卜毒

ク 犬 際ビ稀犬國

土 宜 $=$ 彼大東 $=$

ン シ實カリ西侵

ッ 》驗侵キ南入

王需

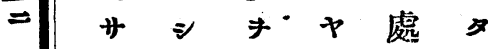

就、モ被幸卜ル

F $, 2, \Rightarrow \frac{1}{1}$

一 $\Rightarrow \bar{\nabla}$ テ

二 カ 由 ザ

ラテル其報ル

實 ザ 將心跡二

驗ル桃 $\neq \neq$ 接

ノ, ヤ絕七中

業侵是タザ ア

ナ襲レンルハ

ラ $\Rightarrow$ 期トナ我

$ン$ 具 $\approx \geqslant \geqslant$ 同

フ難卜新胞

ル 踓聞

八事代 $\Rightarrow$ 苦

决䨘今嚁 シ

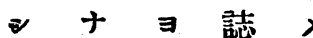

平

$\overline{\overline{+}}$

₹ $), y=$

無 數之心

而 レ年 $キ 1$

二小 乃記夫

>吾至七レ 三

ラ人十ザ 幾

ザ カ 數 ル 許
附末山然務才

シ恕次》メヤ

顧 大 然 $テ$ 决

(2) 5 可, $\nu$ 其 $\approx$

サ $シ \boldsymbol{P}$ 食テ

ル. 然 7 若餪怪

$=2 \cdots \equiv$ 妓訝

於氏其之比

テ其罪 キ攝ル

八是醫 等 生 =

决非 = 閑法足

シ $ま$ 非 $\Rightarrow$ キ

テ制

恕定 $大$ 查几

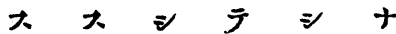

可ッ ₹ 顧以以

カ) 何 三 テ 故

ラ 裁 У ス之

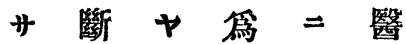

几力俗 メ適 タ

ナキ人

》有, 患,

大之者方,

ル $ま$ 法 若

醫 知 $\approx * \approx$

二 ラ テ 講 斯

７失也心

テ $ン$ 明 サ 患

若テ， 者

* 行 不可 $P$

之フ幸力为

ま 小 $\Rightarrow=$

等其陷 大會

閑媻 ラ夫

＼cjkstart佔シレ心 